\title{
Recent Publications
}

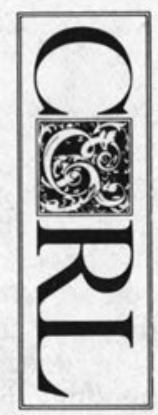

\section{BOOK REVIEWS}

Oboler, Eli M. To Free the Mind: Libraries, Technology, and Intellectual Freedom. Littleton, Colo.: Libraries Unlimited, 1983. 137p. \$15. ISBN 0-87287-325-0.

Eli Oboler died before he finished writing this book on a subject that dominated his personal and professional lifeintellectual freedom. In this short piece the author explores the impact of technology on intellectual freedom. He warns us that our present courtship of technology must be pursued with extreme caution lest we find that the embrace smothers all that is best of the humanist heritage in librarianship.

In Oboler's interpretation of the uneasy marriage between libraries and technology, danger lurks in every bit and byte. A cornerstone of his argument is that since computerization and networking cost a great deal of money, "access is automatically restricted in relation to the amount of money available to any particular library. And denial of access is, of course, one way of restricting intellectual freedom." (p.21). Furthermore, the creation of large databases makes possible massive invasions of privacy.

Were his discourse aimed largely at discussing the relationship between libraries and technology, Oboler's case would be clearer, if not stronger. However, we often find him wandering off to discuss the production of information as opposed to its dissemination. While there is an obvious link between intellectual freedom and unfettered communication, the role of the library is less apparent. As a result of excursions of this type, the book more resembles a potpourri of semidigested thoughts rather than a carefully reasoned and argued discourse. This tendency is reinforced by the frequent inclusions of excerpts of his previously published essays, some having but the most tenuous relationship to the intended thrust of the book.

At times the reader will be tempted to dismiss Oboler's cautions as railings against "willy-nilly modernization." That would be a mistake. His insights about the inherent dangers in "compunication" (the combined effects of computerized data processing and telecommunications) remind us that only our goodwill prevents the use of the machine against individual freedom. And since we hesitate to trust too much to that goodwill, we need a voice such as Oboler's. In the struggle between people and machine, people must prevail.-Jay Whaley, University of California, Irvine.

Dowlin, Kenneth E. The Electronic Library:

The Promise and the Process. New York: Neal-Schuman, 1984. 199p. \$24.95. LC 83-21957. ISBN 0-918212-75-8.

Most of the serious interest to date in "the electronic library" has come from public libraries. The inherent conservatism of scholarship has buffered academic libraries from some of the electronic winds of change. Community college and undergraduate libraries, coping with the computer-literate products of secondary schools, have been more quickly affected than university and research libraries. Ultimately, however, all libraries will have to deal with the odd shapes and sizes, complex "reading" equipment, and different organizations of the newer forms of "publication." 
Perhaps most critical from any academic library viewpoint is the volatile nature of many electronic publications. Our scholarly apparatus has grown up in a world of edition printing. How does one cite texts that may change from minute to minute? How does one cite specific passages of nonlinear text?

Ken Dowlin's Electronic Library is a good starting place for those who are just beginning to address the impact of the new electronic forms of publication on their libraries. The work is largely jargon-free, and takes a managerial rather than technical approach.

The first four chapters provide a broad overview of the problems and challenges of the emerging electronic age. In chapter one, "Is the Third Wave for Real?" Toffler's third-wave thesis is presented along with discussion of its implications for library service and some examples of library and information system experiments. Chapter two focuses on "The Role of Information in the Electronic Age," while chapter three extends the discussion to "The Role of Libraries and Librarians in the Electronic Age." Having made his arguments for the necessity for change,
Dowlin then addresses "The Need for Change in Library and Information Service Organizations,"' in chapter four. These chapters are concise and well written, and the references offer guidance for further reading.

In "The Application of Systems Theory," basic concepts of systems theory, strategic planning, budgeting, project management, operational control, and networking are laid out. Chapter six, "Hardware," contains an interesting discussion of advantages and disadvantages of various media. "Skills," discussed in chapter seven, include planning, decision making, organizational development, team building, communication, and process management. These middle chapters will be most useful for the novice reader.

Chapter eight briefly comments on professional associations, standards, and new paradigms needed as part of "A Professional Strategy for the Future of Library and Information Service." Chapter nine, "The Promise," is a thin grab bag of scattered but pithy comments on access, communication, linking, image, leverage, funding, and power.

The final chapter discusses "Maggie's

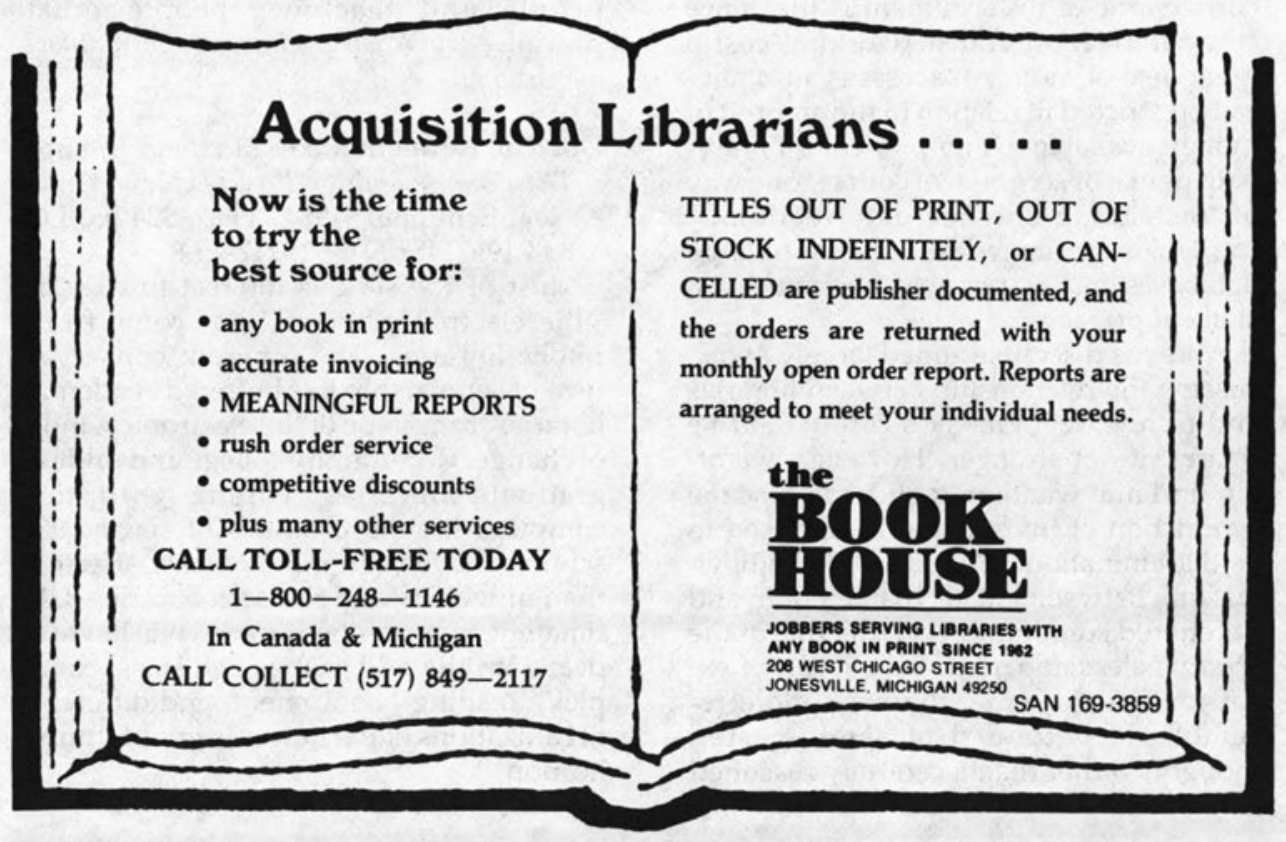


Place: A Prototype?" While forty pages are too few to give a detailed understanding of the Pikes Peak Library District system, it does offer a paragraph or two about each of the various applications supported. The twenty-nine figures in chapter ten are very useful for understanding the complex mix of tasks Maggie's Place performs. As Dowlin suggests, the system probably "better approximates the model of the electronic library than any other... institution in the country" today.

Dowlin's book is an excellent starting point for someone new to electronic library concepts. It is a useful crib sheet for public librarians trying to develop their own plans for the future. While not aimed primarily at academic librarians, they will nonetheless find it a source of quotable quotes and challenging ideas. Those planning for online catalogs will find it very useful in listing the varieties of information resources with which future library catalogs must cope.

The format is attractive, illustrations well chosen and well reproduced, typos infrequent, index good, and price quite reasonable.-Brian Aveney, Blackwell North America.

\section{ABSTRACTS}

The following abstracts are based on those prepared by the ERIC Clearinghouse of Information Resources, School of Education, Syracuse University.

Documents with an ED number here may be ordered in either microfiche (MF) or paper copy (PC) from the ERIC Document Reproduction Service, P.O. Box 190, Arlington, VA 22210. Orders should include ED number, specify format desired, and include payment for document and postage.

Further information on ordering documents and on current postage charges may be obtained from a recent issue of Resources in Education.

\section{National Library Service for the Blind and} Physically Handicapped. Working Paper. Battelle Memorial Institute, Columbus, Ohio. Columbus Labs; Library of Congress, Washington, D.C., National Library Service for the Blind and Physically Handicapped. 1983. 60p. ED 232 646. MF-\$0.83; PC- $\$ 4.82$.

Based on observations made at the National Library Service for the Blind and Physically Handicapped (NLS/BPH) on September 8, 9, and 10,1982 , and on documents supplied by $\mathrm{NLS} / \mathrm{BPH}$, this report compares standards published in the 1979 document entitled "Standards of Service for the Library of Congress Network of Libraries for the Blind and Physically Handicapped" with five areas of NLS/BPH operations: (1) organization, administration, budget, and planning; (2) personnel and facilities; (3) resource development; (4) service to users; and (5) public education and information services. It is noted that NLS/BPH provides braille materials, cassettes, hard- and flexible-disk books, playback equipment and accessories, musical scores, books about music, and music instructional materials to eligible Americans living in the United States and abroad, by means of a cooperative network of libraries. The report states that NLS/BPH meets all the major standards for resource development and user service and that it meets or exceeds most of the other required standards. An NLS/BPH organizational chart and a list of nine recommendations for improving the internal operation of NLS/BPH and its service to the network are provided.

Back to the Books: Bibliographic Instruction and the Theory of Information Sources. Ed. by Ross Atkinson. Association of College and Research Libraries, Bibliographic Instruction Section, Chicago. 1983. 79p. ED $232655 \mathrm{MF}-\$ 0.83$; PC-not available from EDRS.

This collection of four papers on the applicability of bibliographic theory to bibliographic instruction is introduced by Ross Atkinson, who sees a shift away from political and pedagogical concerns in bibliographic instruction. In "Pragmatic Bibliography," Patrick Wilson contrasts wholesale or comprehensive bibliography (the compilation of national and trade bibliographies, library catalogs, and abstracting and indexing journals) with pragmatic bibliography (the activity of one person engaged in a specific limited inquiry). Frances L. Hopkins, in "Bibliographic Instruction as a Liberal Art: An Ap- 